\title{
An integrated approach for supply-production planning in a supply chain
}

\author{
Mohammad Sabet Motlagh $^{\mathrm{a}^{*}}$, Masoud Rezaei ${ }^{\mathrm{b}}$ and Mahdi Abedini Naeeni ${ }^{\mathrm{c}}$
}

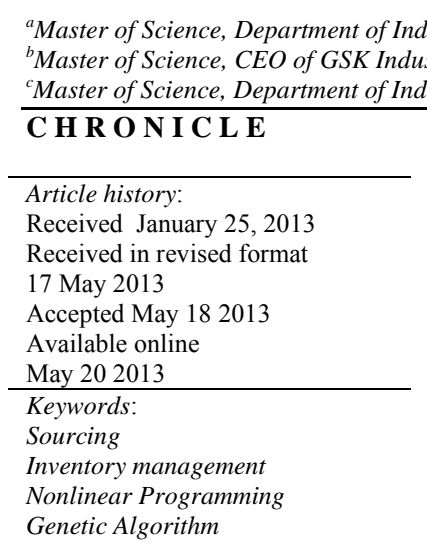

\begin{abstract}
Many firms try to optimize their supply and production levels separately, but this method could limit influence profitability, negatively. Thus, it is becoming more important to analyze these two levels, simultaneously. In this paper, an integrated supply-production planning is considered, simultaneously. We develop a mathematical model, which calculates the optimal inventory lot sizing for each supplier and minimizes the total cost associated with the process of procuring raw material, transferring and holding raw materials and manufacturing. The problem is formulated as a nonlinear programming and heuristic genetic algorithm (GA) method is developed to solve the resulted problem. We examine the performance of the proposed model for a case study conducted in Iran. Experimental results show that such a model can reduce the costs of the case study, substantially.
\end{abstract}

\section{Introduction}

During the past few years, there has been growing interest on supply chain (SC) and supply chain management (SCM) problems. Nevertheless, SC and its activities in some of firms have not been implemented yet. Kabossa (2003) stated that managers have to change their thinking about the purchasing and supply chain functions, to see it as strategic and not clerical; and purchasing and supplies personnel need training in supply chain management. A supply chain is a network of suppliers, manufacturing facilities, distribution centers, and retailers, which performs the functions of procurement of materials, transformation of these materials into intermediate and finished product, and the distribution of these finished products to customers. A supply chain may exist in both service and manufacturing organizations. An efficient supply chain system operates under a strategy to minimize costs by integrating various functions inside the system and by meeting on time customers' needs. Many manufacturing operations are designed to maximize throughput and lower expenses associated with inventory levels and distribution. Therefore, it has been an important issue to

*Corresponding author.

E-mail addresses: syahkaly@gmail.com (M. Sabet Motlagh) 
integrate inventory decisions in SCM. An effective control of inventory systems increases the production efficiency of a system. A system, which incorporates excess inventory, reflects insufficient planning and poor communication and management.

The present paper considers an assembly production system, where the producer uses several raw materials to convert into finished product. Raw materials are divided into two types; some of the raw materials require preprocessing before final stage assembling and some of the materials do not need any transformation or preprocessing, but they are used in an assembly line to produce products. Moreover, there are two categories of inventories including raw materials and work-in-process inventories. The operational activities of the SC inventories include: (1) Raw materials: inventory planning, purchasing, transportation from suppliers to firm. (2) Work-in-process (WIP): processing and/or preprocessing inside the manufacturing unit. Therefore, any SC system considered in this research consists of two levels: suppliers and producer.

The purpose of this paper is to develop a mathematical model to calculate the optimal inventory lot sizing for each supplier and to minimize the total cost associated with the process of procuring raw material, transferring and holding raw materials and manufacturing. It also attempts to find operational plans to increase the efficiency of the firms by reducing the level of wasted materials and time and effort involved at each of the supply chain levels. Then the model is solved by applying heuristic genetic algorithm method.

\section{Literature review}

In supply chain model of assembly system, most of the researchers discussed the impact of their inventory decisions on total cost function, and mathematical models are formulated to achieve the cost reductions by optimizing the system parameters and/or the operation sequences. Batch size, order rate, production lead-time, work-in-process inventory, delivery lead times and development of suitable mathematical models for the solution are the major concern of the models. Samaranayake (2005) presented a conceptual framework for the supply chain. The aims of the research were to develop an integrated framework, and to provide a methodology for planning many components in the supply chain such as suppliers, materials, resources, warehouses, activities and customers. The proposed framework is based on the unitary structuring technique where bills of materials, bills of warehouses, project networks and operations routings, in both manufacturing and distribution networks are combined into a single structure. Axsäter and Juntti (1996) presented the relative cost difference between the level stock or installation stock reorder policies in a multi-level inventory system for a constant demand. The echelon stock or installation stock policy may be advantageous depending on the structure of the system. Gurnani et al. (1996) considered an assembly problem of two critical components where demand of finished product is stochastic and delivery can be completed in the next cycle. A computational study is conducted to determine the effect of supplier costs and the probability of delivery on the optimal order policy. Rosenblatt and Lee (1996) considered assembly systems of highly expensive components (e. g. aerospace industry) with longer cycle time in which product's value increases the necessity to install additional parts and labor while moving along the assembly line. A branch-and-bound procedure is used to minimizes inventory holding cost and showed sequencing of ascending values of the ratios of the 'value added' to activity duration. Daning and Derek (1997) showed an assembly production/inventory system of constant demanded final product with backlogging allowed. The number of series systems is proportional to, in the extreme case, the factorial of n nodes in the assembly system. The lower bound and the optimal lot-size frequency policy for assembly systems with backlogging are also17 illustrated. Fujiwara et al. (1998) considered a Kanban-controlled, multi-stage production assembly system where raw materials acquisition lead times, reorder points, number of Kanbans, production lead time and demand arrival are the design parameters and variables. Mathematical model and simulation analyses are proposed to evaluate system performance measures. 
Powell and Pyke (1998) addressed unbalanced assembly systems with limited buffer capacity. Heuristic rules were developed to improve existing operations and to introduce new products. Wilhelm and Pradip (1998) considered the performance measure of a single-stage, single-product, and stochastic assembly system where raw materials are ordered under the material requirement planning (MRP) policy, and the inventory position process is a Markov renewal process and production lead-time is a random variable. Sarker and Pan (1998) developed a mixed-model SC system with a close and open station assembly line format. The minimum total expenditure was determined in the open-station system for a given line length and operation sequences. De Kok and Ton (1999) proposed multi-echelon assembly systems where components were assigned to finished product. The comparison of proposed pre-allocation policies with several commonly used allocation policies was presented in their research. Park and Kim (1999) concentrated on a make to order policy in an assembly system where delivery dates were considered as constraints. A non-linear mathematical model was presented to minimize the holding costs of the inventories and the experimental results were examined, properly. Park and Kim (2000) extend Park and Kim's (1999) model developing a mixed integer linear programming model. They incorporated the 'branch and bound' (B\&B) algorithm to find the integer solutions. Agrawal and Cohen (2001) analyzed the costservice performance and component inventory policies arises for shortages and delayed production completion rates of finished product. Togar et al. (2004) stated that SC coordination could play a critical role in integrating various actors along the supply chain to enhance performance. They concentrated on SC coordination and its three determinants: namely, responsibility interdependence, uncertainty, and inter-functional conflict. Research propositions were developed to conceptualize how SC coordination could be driven by its determinants. The propositions were examined by a case study in a fashion firm to investigate the differences between the theory and the practice of coordination and they reported that the firm carried out only piecemeal coordination in defining and fulfilling customer needs.

Nonino and Panizzolo (2007) empirically investigated the criticalities of a production system constrained by distribution, in order to propose a model for integrating production and distribution planning for a simultaneous improvement in terms of efficiency and efficacy. They also proposed three solutions for a better integration of production-distribution systems are proposed in terms of various levels of benefits and complexity. Bhakoo et al. (2012) presented an inventory management model for service organization. They developed a framework for collaborative arrangements partners in Australian hospital supply chains to manage inventories. Nasiri et al. (2010) formulated an integrated model for the location of warehouse, the allocation of retailers to the opened warehouses, and determined perfect policy for inventory control to manage order quantity and safety stock level. The objective was to select the optimum numbers, locations, capacities of the opening warehouses and inventory policy so that all stochastic customer demands can be satisfied.

\section{Supply and Production problem in supply chain}

The decisions for all SC system are classified into three categories of strategic, tactical and operational. These decisions are basically made over a long time horizon, and these are linked to the corporate strategy to guide SC policies in terms of design perspective. On the other hand, the function of operational decisions includes short-term objectives and focuses on activities over a day-to-day basis. The operational level of a SC requires managers to determine the amount of raw materials used to produce parts or products and the amount of parts used in the production of final products. It also includes the amount of final products, the amount of raw materials and intermediate parts, final products to hold at various locations in inventory and the amount of final products to distribute among distributors. Moreover, the tactical level falls in between those two levels.

Many models have been formulated for the operational level of supply chains. Supply and Production problem is included in the operational planning level. A conventional supply-production chain 
consists of independent suppliers, manufacturers and each is a separate business entity seeking to maximize its own profits. However, SCM includes the suppliers of the manufacturer in the same framework and aims to coordinate the activities of all members of chain. To illustrate modeling of the integrated supply and production problem in SC, we consider a multi-period, multi-product and multi supplier problem. The structure of the proposed system in supply chain environment is described in Fig. 1.

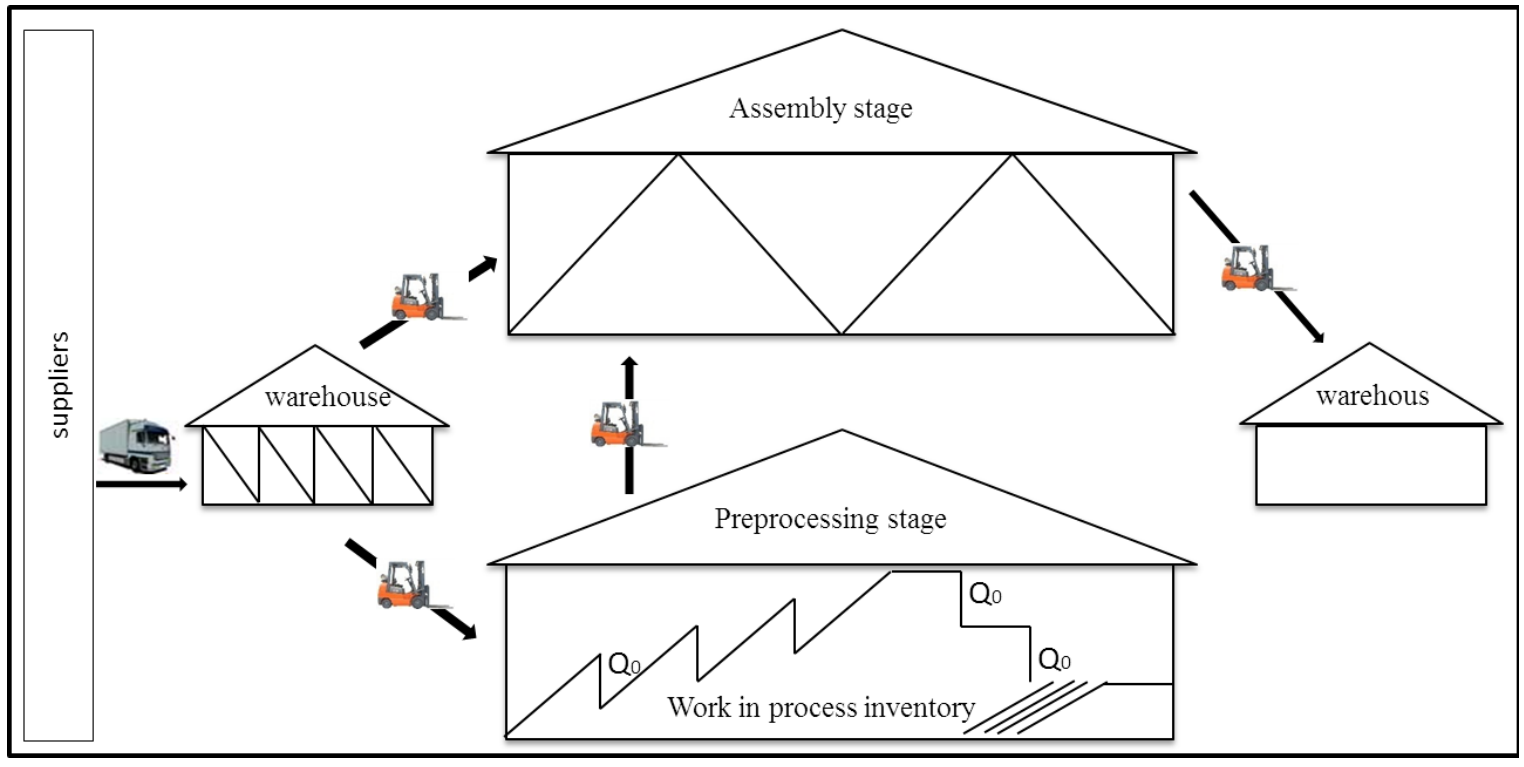

Fig. 1. Supply-production and distribution system in supply chain under study

As we can observe from Fig. 1, the proposed SC system consists of two plants or stages. The first plant of production system (preprocessing stage) produces $J$ different parts used in the production of $P$ various products at the second plant (assembly stage) of production system. In addition, the firm purchases several raw materials from suppliers to convert into finished product, some of the raw materials require preprocessing before final stage assembling and some of the materials are ready to be used in an assembly line to produce final products. The distribution system contains a stack buffer where all products produced in production system are temporarily stored. The problem is to meet the production requirements at minimum overall costs of supply, production and inventory, subject to various resource constraints.

\section{Model development}

The mathematical model is developed using the following assumptions and notations:

\section{Assumptions}

Production rate is higher than demand rate so the products are accumulated in the system. Production capacity is fixed.

Initially the system contains stock.

Demand of products in period is known over a planning horizon.

All requirements must be fulfilled in the period in which they occur: backordering is not allowed.

Available total storage space is limited. 


\section{Notations}

The notations used in this model are three kinds, (I) indices; (II) parameters, which are known and given values; (III) variables, which are unknown. The objective of this model is to determine the variables. The following are the indices, parameters and variables used in this model.

\section{Indices:}

i $\quad 1 . . . I$ index of item

$j \quad 1 \ldots J$ index of parts that are produced within the plant

$t \quad 1 \ldots T$ index of time periods

$s \quad 1 \ldots S$ index of suppliers

p $\quad 1 \ldots P$ index of products

$e \quad 1 \ldots E$ index of workstations

w $\quad 1 \ldots W$ index of warehouses

\section{Parameters}

$\mathrm{CB}_{\text {ist }}$ : unit Purchase price of item $i$ from supplier $s$ in period $t$,

$\mathrm{CT}_{\mathrm{ist}}$ : unit Transportation cost of item $\mathrm{t} i$ from supplier $\mathrm{s}$ in period $t$,

$\mathrm{CH}_{\mathrm{iwt}}$ : unit Holding cost of item $i$ at warehouse $w$ in period $t$,

$\mathrm{CH}_{\mathrm{jwt}}$ : unit Holding cost of part $j$ at warehouse $w$ in period $t$,

$\mathrm{CH}_{\text {pwt }}$ : unit Holding cost of product $p$ at warehouse $w$ in period $t$,

$\mathrm{r} \quad$ :Rate of holding cost,

$\mathrm{SS}_{\text {it }} \quad$ :Safety Stock of item $i$ in period $t$,

$\mathrm{SS}_{\mathrm{jt}} \quad$ :Safety Stock of part $j$ in period $t$,

$\mathrm{SS}_{\mathrm{pt}} \quad$ :Safety Stock of product $p$ in period $t$,

$\mathrm{CS}_{\mathrm{iwt}} \quad$ :Shortage cost per unit of item $i$ at warehouse $w$ in period $t$,

$\mathrm{CS}_{j \mathrm{jt}} \quad$ :Shortage cost per unit of part $j$ at warehouse $w$ in period $t$,

$\mathrm{CS}_{\mathrm{pwt}}$ :Shortage cost per unit of product $p$ at warehouse $w$ in period $t$,

$\mathrm{CO}_{\text {st }}$ :Transaction cost for supplier $s$ in period $t$,

$\mathrm{CP}_{\text {jet }} \quad$ :cost of processing per unit of part $j$ at workstation $e$ in period $t$,

$\mathrm{CP}_{\text {pet }} \quad$ :cost of processing per unit of product $p$ at workstation $e$ in period $t$,

$\mathrm{D}_{\mathrm{jt}} \quad$ :Demand of part $j$ in period $t$,

$\mathrm{D}_{\mathrm{pt}} \quad$ :Demand of product $p$ in period $t$,

$\mathrm{P}_{\mathrm{jt}} \quad$ :Production rate at preprocessing stage (part $j$ ) in period $t$,

$\mathrm{P}_{\mathrm{pt}} \quad$ :Production rate at assembly stage (part $j$ ) in period $t$,

$\mathrm{n}_{\mathrm{ip}} \quad$ :Number of units of item $i$ used to make one unit of product $p$

$\mathrm{n}_{\mathrm{jp}} \quad$ :Number of units of part $j$ used to make one unit of product $p$

$\mathrm{C}_{\text {st }} \quad$ :Capacity of $S^{\text {th }}$ supplier in each period,

$\mathrm{PC}_{\text {et }}$ :Capacity of $e^{\text {th }}$ workstation (preprocessing stage) in period $t$,

$\mathrm{AC}_{\text {et }}:$ Capacity of $e^{\text {th }}$ workstation (assembly stage) in period $t$,

$\mathrm{M}: \quad$ :A large number,

$\mathrm{IWC}_{\text {it }}$ :Storage space item $i$ in period $t$,

$\mathrm{JWC}_{\mathrm{jt}} \quad$ :Storage space part $j$ in period $t$,

$\mathrm{PWC}_{\mathrm{pt}}$ :Storage space product $p$ in period $t$,

$\mathrm{B}_{\mathrm{s}} \quad$ :Minimum order quantity to the supplier $s$

\section{Variables}

$\mathrm{X}_{\mathrm{ist}}$ :number of item $i$ ordered from supplier $s$ in period $t$

$\mathrm{XX}_{\mathrm{j}}$ :number of part $j$ produced at workstation $e$ in period $t$

$\mathrm{z}_{\mathrm{pet}}$ :number of product $p$ produced at workstation $e$ in period $t$

$\mathrm{I}_{\text {it }} \quad$ :amount of inventory of item $i$ in period $t$

$\mathrm{I}_{\mathrm{jt}} \quad$ :amount of inventory of part $j$ in period $t$

$\mathrm{I}_{\mathrm{pt}} \quad$ :amount of inventory of product $p$ in period $t$

$\mathrm{S}_{\mathrm{iw} 1}$ :amount of shortage of item $i$ at warehouse $w$ in period $t$

$S_{j w 1}$ :amount of shortage of part $j$ at warehouse $w$ in period $t$

$\mathrm{S}_{\mathrm{pw}}$ :amount of shortage of product $p$ at warehouse $w$ in period $t$ 
$\mathrm{Y}_{\mathrm{st}}=1$ if an order is placed on supplier $\mathrm{s}$ in time period $\mathrm{t}$ or 0 otherwise

Regarding the above notations, the nonlinear programming is formulated as follows:

$$
\begin{gathered}
\mathrm{TC}_{1}=\sum_{\mathrm{i}=1}^{\mathrm{I}} \sum_{\mathrm{s}=1}^{\mathrm{S}} \sum_{\mathrm{t}=1}^{\mathrm{T}} \mathrm{CB}_{\mathrm{ist}} \mathrm{X}_{\mathrm{ist}}+\sum_{\mathrm{i}=1}^{\mathrm{I}} \sum_{\mathrm{s}=1}^{\mathrm{S}} \sum_{\mathrm{t}=1}^{\mathrm{T}} \mathrm{CT}_{\mathrm{ist}} \mathrm{X}_{\mathrm{ist}}+\sum_{\mathrm{t}=1}^{\mathrm{T}} \sum_{\mathrm{i}=1}^{\mathrm{I}} \mathrm{CH}_{\mathrm{iwt}}\left[\frac{\left.\sum_{\mathrm{s}=1}^{\mathrm{S}} \mathrm{X}_{\mathrm{ist}}+\mathrm{I}_{\mathrm{it}-1}+\mathrm{SS}_{\mathrm{it}}\right]+\sum_{\mathrm{i}=1}^{\mathrm{I}} \sum_{\mathrm{t}=1}^{\mathrm{T}} \mathrm{CS}_{\mathrm{iwt}} \mathrm{S}_{\mathrm{iwt}}}{2}\right. \\
+\sum_{\mathrm{t}=1}^{\mathrm{J}} \sum_{\mathrm{s}}^{\mathrm{T}} \mathrm{CO}_{\mathrm{st}} \mathrm{Y}_{\mathrm{st}} \\
\mathrm{TC}_{2}=\sum_{\mathrm{j}=1}^{\mathrm{J}} \sum_{\mathrm{t}=1}^{\mathrm{T}} \mathrm{CP}_{\mathrm{jet}} \mathrm{XX}_{\mathrm{jet}}+\sum_{\mathrm{t}=1}^{\mathrm{T}} \sum_{\mathrm{j}=1}^{\mathrm{J}} \mathrm{CH}_{\mathrm{jwt}}\left[\frac{\mathrm{XX}_{\mathrm{jet}}+\mathrm{II}_{\mathrm{jt}-1}+\mathrm{SS}_{\mathrm{jt}}}{2}\left(1+\frac{1}{\mathrm{n}}-\frac{\mathrm{D}_{\mathrm{jt}}}{\mathrm{P}_{\mathrm{jt}}}\right)\right]+\sum_{\mathrm{j}=1}^{\mathrm{J}} \sum_{\mathrm{t}=1}^{\mathrm{T}} \mathrm{CS}_{\mathrm{jwt}} \mathrm{S}_{\mathrm{jwt}} \\
\mathrm{TC}_{3}=\sum_{\mathrm{p}=1}^{\mathrm{P}} \sum_{\mathrm{t}=1}^{\mathrm{T}} \mathrm{CP}_{\mathrm{pet}} \mathrm{Z}_{\mathrm{pet}}+\sum_{\mathrm{t}=1}^{\mathrm{T}} \sum_{\mathrm{p}=1}^{\mathrm{P}} \mathrm{CH}_{\mathrm{pwt}}\left(\frac{\mathrm{Z}_{\mathrm{pet}}+\mathrm{III}_{\mathrm{pt}-1}+\mathrm{SS}_{\mathrm{pt}}}{2}\right)\left(1-\frac{\mathrm{D}_{\mathrm{pt}}}{\mathrm{P}_{\mathrm{pt}}}\right)+\sum_{\mathrm{j}=1}^{\mathrm{J}} \sum_{\mathrm{t}=1}^{\mathrm{T}} \mathrm{CS}_{\mathrm{pwt}} \mathrm{S}_{\mathrm{pwt}}
\end{gathered}
$$

minmize $\mathrm{TC}=\mathrm{TC}_{1}+\mathrm{TC}_{2}+\mathrm{TC}_{3}$

Subject to :

$$
\begin{aligned}
& \sum_{S=1}^{S} X_{i s t}+I_{i t-1}-I_{i t}=\sum_{p=1}^{P} n_{i p} X_{\text {pet }} \quad \text { for all } i \text { and } t \\
& \mathrm{XX}_{\mathrm{jet}}+\mathrm{II}_{\mathrm{jt}-1}-\mathrm{II}_{\mathrm{jt}}=\sum_{\mathrm{p}=1}^{\mathrm{P}} \mathrm{n}_{\mathrm{jp}} \mathrm{Z}_{\mathrm{pet}} \quad \text { for all } \mathrm{j} \text { and } \mathrm{t} \\
& \sum_{i=1}^{I} X_{i s t} \leq C_{s t} Y_{s t} \\
& \sum_{\mathrm{j}}^{\mathrm{J}} \mathrm{XX}_{\mathrm{jet}} \leq \mathrm{PC}_{\mathrm{et}} \\
& \text { for all } \mathrm{s} \text { and } \mathrm{t} \\
& \text { for all e and } t \\
& \sum_{\mathrm{p}}^{\mathrm{P}} \mathrm{Z}_{\text {pet }} \leq \mathrm{AC}_{\mathrm{et}} \\
& \text { for all e and } t \\
& \mathrm{I}_{\mathrm{it}} \geq \mathrm{SS}_{\mathrm{it}} \\
& \text { for all } \mathrm{i} \text { and } \mathrm{t} \\
& \mathrm{II}_{\mathrm{jt}} \geq \mathrm{SS}_{\mathrm{jt}} \\
& \text { for all } \mathrm{j} \text { and } \mathrm{t} \\
& \mathrm{III}_{\mathrm{pt}} \geq \mathrm{SS}_{\mathrm{pt}} \\
& \text { for all } p \text { and } t \\
& \sum_{\mathrm{S}=1}^{\mathrm{S}} \mathrm{X}_{\mathrm{ist}}+\mathrm{I}_{\mathrm{it}-1} \leq \mathrm{IWC}_{\mathrm{it}} \\
& \text { for all } \mathrm{i} \text { and } \mathrm{t}
\end{aligned}
$$




$$
\begin{aligned}
& \mathrm{XX}_{\mathrm{jet}}\left(1-\frac{\mathrm{D}_{\mathrm{jt}}}{\mathrm{P}_{\mathrm{jt}}}\right)+\mathrm{II}_{\mathrm{jt}-1} \leq \mathrm{JWC}_{\mathrm{jt}} \quad \text { for all } \mathrm{j} \text { and } \mathrm{t} \\
& \sum_{p=1}^{P}\left(Z_{p e t}\left(1-\frac{D_{p t}}{P_{p t}}\right)+I I I_{p t-1}\right) \leq P C_{p t} \quad \text { for all } t \\
& \left(\sum_{i=1}^{I} X_{i s t}-B_{s}\right) Y_{s t}+\left(B_{s}-\sum_{i=1}^{I} X_{i s t}\right)\left(1-Y_{s t}\right) \geq 0 \quad \text { for all s and } t \\
& \sum_{\mathrm{P}=1}^{\mathrm{P}} \mathrm{n}_{\mathrm{ip}} \times \mathrm{D}_{\mathrm{pt}}-\left[\sum_{\mathrm{S}=1}^{\mathrm{S}} \mathrm{X}_{\mathrm{ist}}+\mathrm{I}_{\mathrm{it}-1}+\mathrm{n}_{\mathrm{ip}} \times \mathrm{I}_{\mathrm{pt}}\right]=\mathrm{S}_{\mathrm{iwt}} \quad \text { for all } \mathrm{i} \text { and } \mathrm{t} \\
& \sum_{P=1}^{P} n_{j p} \times D_{p t}-\left[\sum_{j=1}^{J} X X_{j e t}+I_{j t-1}+n_{j p} \times I_{p t}\right]=S_{j w t} \quad \text { for all } j \text { and } t \\
& \mathrm{D}_{\mathrm{pt}}-\left[\mathrm{Z}_{\mathrm{pet}}+\mathrm{I}_{\mathrm{pt}-1}\right]=\mathrm{S}_{\mathrm{pwt}} \quad \text { for all } \mathrm{p} \text { and } \mathrm{t} \\
& \mathrm{X}_{\mathrm{ist}}, \mathrm{I}_{\mathrm{it}}, \mathrm{S}_{\mathrm{iwt}} \geq 0 \quad \text { and integer for all } \mathrm{i}, \mathrm{s}, \mathrm{w}, \mathrm{t} \\
& \mathrm{X}_{\mathrm{jet}}, \mathrm{II}_{\mathrm{jt}}, \mathrm{S}_{\mathrm{jwt}} \geq 0 \quad \text { and integer for all } \mathrm{j}, \mathrm{e}, \mathrm{w}, \mathrm{t} \\
& \mathrm{X}_{\mathrm{pet}}, \mathrm{III}_{\mathrm{pt}}, \mathrm{S}_{\mathrm{pwt}}, \mathrm{X}_{\mathrm{pdt}} \geq 0 \quad \text { and integer for all } \mathrm{p}, \mathrm{e}, \mathrm{w}, \mathrm{t} \\
& \mathrm{Y}_{\mathrm{st}}=(0 \text { or } 1) \quad \text { for all } \mathrm{s}, \mathrm{t}
\end{aligned}
$$

The objective function as shown in Eq. (1) consists of three parts. The first part $\left(\mathrm{TC}_{1}\right)$ consists of: purchase cost of the items from suppliers, the transaction cost for the suppliers, transportation cost of items that purchased from suppliers, holding cost and shortage cost of items. The second part $\left(\mathrm{TC}_{2}\right)$ consists of: production cost of parts, holding and shortage cost of parts. The third part $\left(\mathrm{TC}_{3}\right)$ consists of: production cost of products, holding and shortage cost of products. Eq. (2) is the balance constraint for the items inventory purchased from suppliers. Eqs. (3) are the balance constraint for the parts and products inventory produced at firms. Eq. (4) is the capacity constraint of suppliers, where $\mathrm{M}$ is an arbitrary large number. Eqs. (5) and (6) are workstations capacity constraints. Eqs. (7) - (9) express the inventory levels of items, parts and products in that period. Eqs. (10) - (12) represent the restriction of storage capacity at warehouses. Eq. (13) determines that the amount of orders from each supplier must be more than $B_{s}$. Eqs. (14) - (16) represent the amount of shortage of items, parts and products in that period. Eqs. (17) - (20) enforce the restrictions of non-negativity, integer, and binary nature on the decision variables.

\section{Case study}

In this section, we applied the proposed model to a cost minimization problem of an integrated supply- production system in supply chain of a real case. As described in Fig. 1, the supply system consists of 15 suppliers that provide 12 items for firm. The production system consists of two workstations, the first workstation (preprocessing stage) produce two parts, and the second workstation (assembly stage) produce one product. When parts are processed in the preprocessing plant, are sent directly to the assembly plant buffer and the goods are delivered when the quantity reaches order size. In addition, we consider the model over a planning horizon of three periods. In the following section, we provide a solution methodology for supply- production problem. To this aim, GA is provided to solve it. The details of solution methodology are presented in the following section: 


\section{Genetic algorithms approach}

GA is one of the modern heuristic optimization algorithms widely adopted by researchers in solving various problems. Introduced by Holland (Woarawichai et al., 2010) in 1975, GA heuristic optimization algorithms mimic the mechanism of genetic evolution in nature. In this section, we explain GAs procedure is illustrated in Figure 2. Topics covered include (1) Chromosome structure (2) Initial population (3) Evaluation (4) Selection (5) Crossover (6) Mutation, and (7) Termination rule.

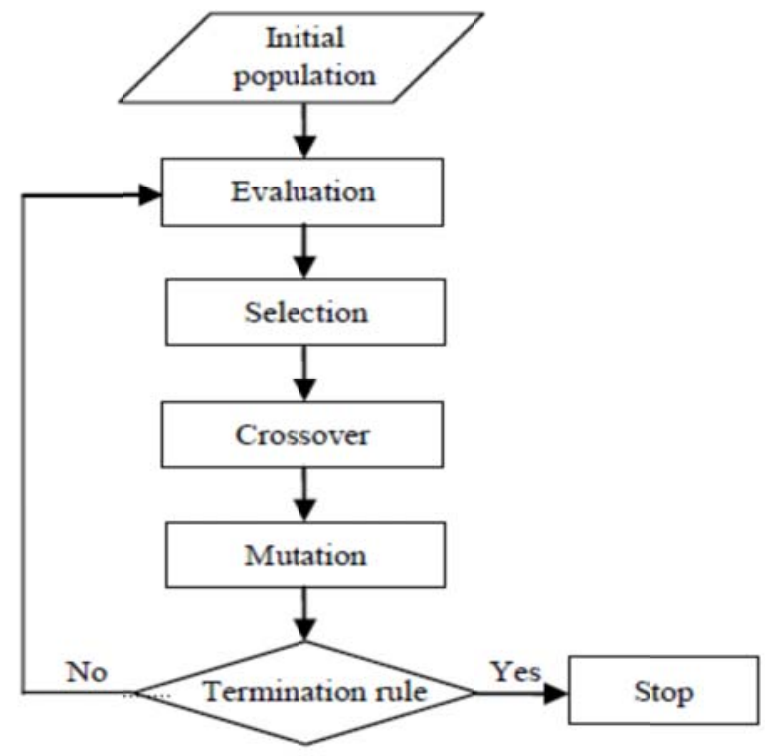

Fig. 2. The genetic algorithm procedure (Woarawichai et al., 2010)

\subsection{Chromosome structure}

Each chromosome is a feasible solution for the model that holds the sum of the numbers of decision variables. In this problem, there are 972 variables, which 714 are integer and 258 are zero or one.

\subsection{Initial population}

The population initialization technique used in the GAs approach is a randomly generate solutions for the entire population. Population size depends only on the nature of problems and it must balance between time complexity and search space measure. More population size may increase the probability of finding optimal solution, but may induce a longer computer time. Here, different amount of primary population are examined to select the most suitable amount of population size.

\subsection{Fitness value or Evaluation}

Fitness value defines the relative strength of a chromosome compared with the others, and the optimality of the solution to the problem. It is evaluated by the chromosome structure, which results in a positive value (Chan et al., 2005). The fitness function of this model is an objective one.

\subsection{Selection}

The selection of parents to produce successive generations plays an extremely important role in the GAs. The goal is to allow the fittest individuals to be selected more often to reproduce. However, all 
individuals in the population have a chance of being selected to reproduce the next generation. In this paper, the roulette wheel selection technique is used (Sarker \& Newton, 2002).

\subsection{Crossover operator}

Crossover operators combine information from two parents in such a way that the two children (solutions for the next population) resemblance to each parent. There are several available methods to do so (Michalewicz, 1994). In this paper, Crossover operators including two point, scatter, and heuristic are used to solve GA.

\subsection{Mutation operator}

Mutation operators alter or mutate one chromosome by changing one or more variables in some way or by some random amount to form one offspring. Mutations operators including Constraint dependent، Gaussian and Adaptive feasible are used to solve GA.

\subsection{Termination rule}

The GAs moves from generation to generation selecting and reproducing parents until a termination criterion is met. The most frequently used stopping criterion is a specified maximum number of generations. In this paper, there are two stop criteria. First, the process is stopped when the number of iterations has reached the maximum generations. Second, the process is stopped when the maximum time exceeds a given value (set at 300 minutes). In order to show the effectiveness of the proposed model, the algorithm is implemented using MATLAB R2012a. The developed problem is run 10 times with different operators and populations. Table 1 indicates the results of GA for each run.

Table 1

Results of GA for each run

\begin{tabular}{|c|c|c|c|c|c|c|}
\hline Row & generation & Pop-size & $\begin{array}{l}\text { Crossover } \\
\text { operators }\end{array}$ & Mutation operators & Fitness function & time \\
\hline 1 & 100 & 100 & scattered & Constraint dependent & $1.9833611213914528 \mathrm{E} 9$ & $06: 42.8$ \\
\hline 2 & 100 & 100 & Two point & Adaptive feasible & 2.211627268.42209E9 & $07: 39.7$ \\
\hline 3 & 100 & 100 & Two point & Constraint dependent & $1.843995063192652 \mathrm{E} 9$ & $08: 09.5$ \\
\hline 4 & 100 & 100 & heuristic & Constraint dependent & $1.957555697268845 \mathrm{E} 9$ & $07: 22.5$ \\
\hline 5 & 100 & 200 & Two point & Gaussian & $1.246362576661985 \mathrm{E} 9$ & infeasible \\
\hline 6 & 100 & 200 & heuristic & adaptive feasible & 1.3431872990152125E9 & $36: 15.6$ \\
\hline 7 & 100 & 200 & scattered & Constraint dependent & $1.678782181648226 \mathrm{E} 9$ & $56: 35.5$ \\
\hline 8 & 100 & 500 & scattered & Constraint dependent & 1.4667114381.38059E9 & $46: 42.8$ \\
\hline 9 & 100 & 500 & Two point & adoptive feasible & 1.8041727218.42209E9 & $57: 59.7$ \\
\hline 10 & 100 & 1000 & scattered & adaptive feasible & $1.5785872590152125 \mathrm{E} 9$ & $56: 17.6$ \\
\hline
\end{tabular}

\section{Findings}

As seen in Table 1, the best possible response has been generated from heuristic crossover operator, adaptive feasible mutation operator and with the population size of 200. The fitness function reductions in generations for the best possible response are shown in Fig 3. In fact, in this paper we could obtain more realistically optimal supply and production plans (SPDP) for the integrated supply chain system. Moreover, Experimental results approve that such a model can reduce the costs of the case study by $0.111635419 \%$ (as shown in Fig 4). Additionally, the computation time when using GAs is also short, making it a very practical means for solving the multiple products and multi-period inventory lot-sizing problem with distribution centers. 


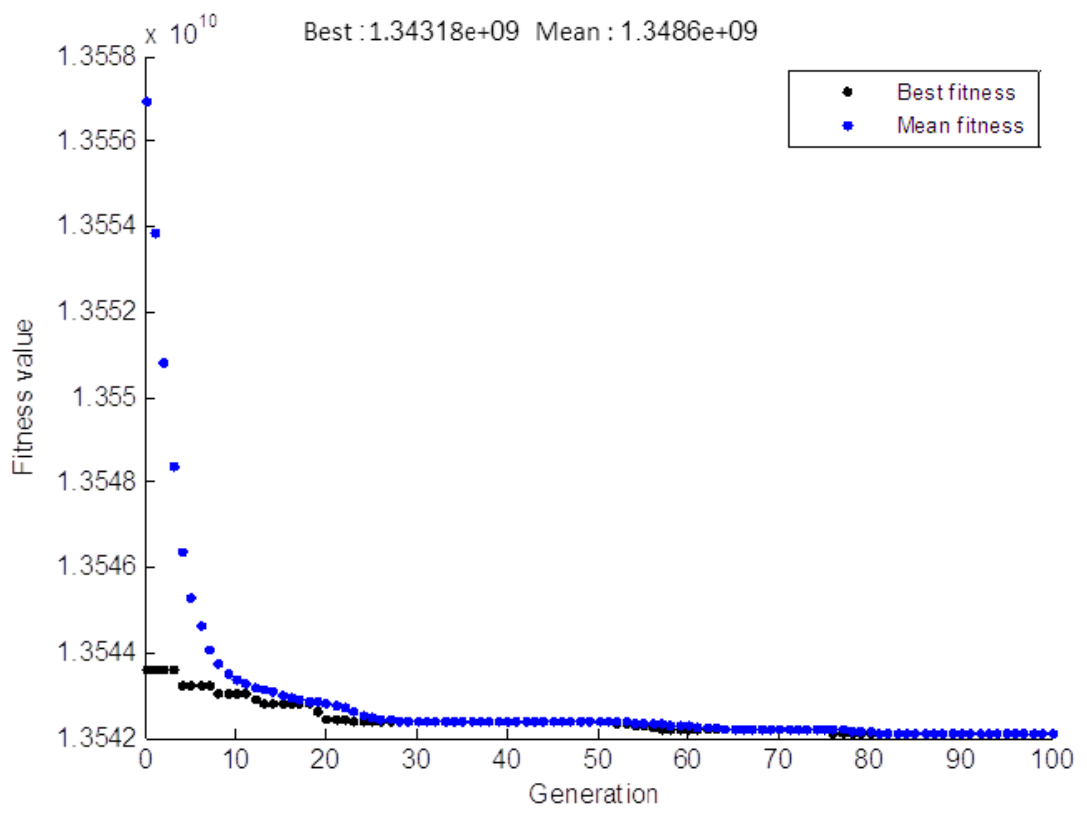

Fig. 3. The fitness function reductions in generations

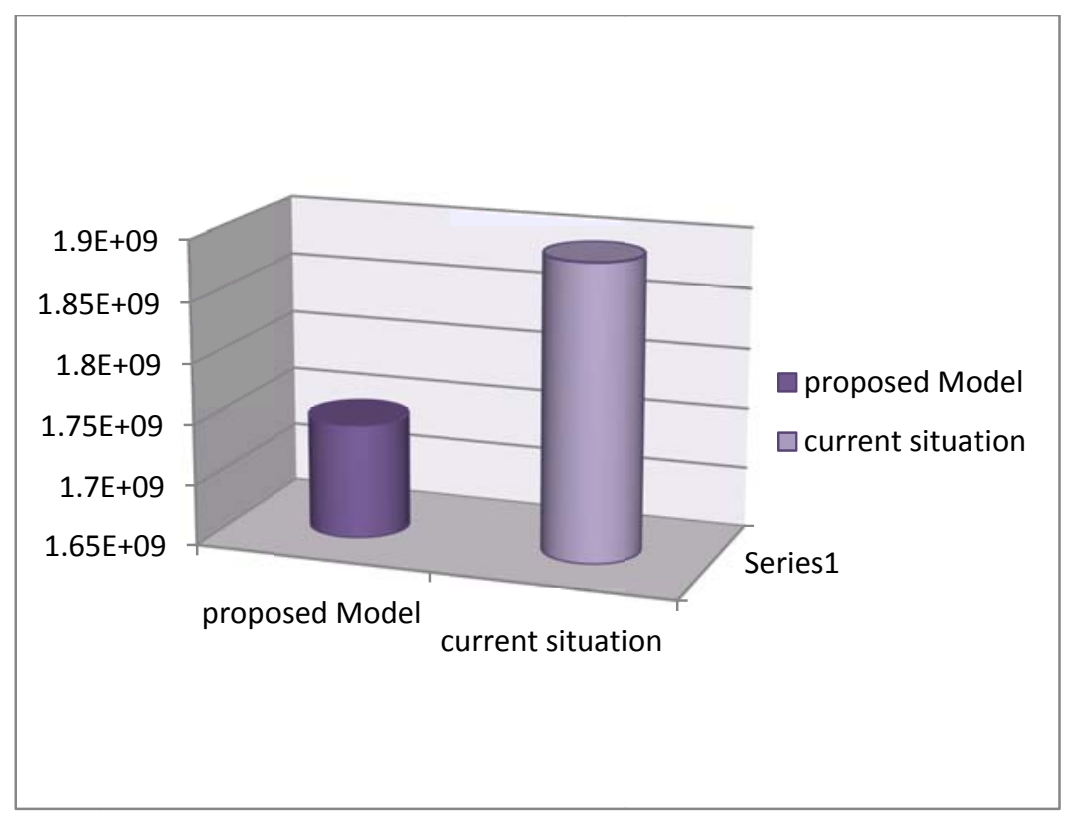

Fig. 4. Current situation vs. proposed model

\section{Conclusions}

Inventories exist at every stage of the supply chain as raw material or semi-finished or finished goods. They can also be as Work-in-process between the stages or stations. Since holding of inventories are capable of causing significant costs, their efficient management is critical in SC operations. Therefore, it has been an important issue to integrate inventory decisions in supply chain system. A system, which provides excess inventory, reflects lack of planning and poor communication and management. The aim of this research was to develop the operation policy of an assembly type, multi-stage supply chain system. The finished product is assembled from a group of raw materials, where some of the raw materials require preprocessing before final stage assembling. It also 
attempted to find a strategic policy to minimize the total cost associated in the process of procuring raw material, transferring and holding raw materials and manufacturing. In fact, in this paper an integrated supply-production planning (SPP) has been considered despite the fact that in most of the Iranian industrial firms, SPP is accomplished. independently. The effective use of integrated SPP not only enhances the performance rather decreases inventory cost, holding cost, shortage cost and overall supply chain costs. A real case has been used to the problem articulation, and then it has been solved by applying heuristic genetic algorithm (GA) method. The proposed model with genetic algorithm could provide the best satisfactory result with the minimum cost. The reliability test was carried by comparing the model results with that of the amount of variables.

\section{References}

Agrawal, N., \& Cohen, M. A. (2001). Optimal material control in an assembly system with component commonality. Naval Research Logistics (NRL), 48(5), 409-429.

Axsäter, S., \& Juntti, L. (1996). Comparison of echelon stock and installation stock policies for twolevel inventory systems. International Journal of Production Economics, 45(1), 303-310.

Bhakoo, V., Singh, P., \& Sohal, A. (2012). Collaborative management of inventory in Australian hospital supply chains: practices and issues. Supply Chain Management: An International Journal, 17(2), 217-230.

Blos, M. F., Quaddus, M., Wee, H. M., \& Watanabe, K. (2009). Supply chain risk management (SCRM): a case study on the automotive and electronic industries in Brazil. Supply Chain Management: An International Journal, 14(4), 247-252.

Chan, F. T., Chung, S. H., \& Wadhwa, S. (2005). A hybrid genetic algorithm for production and distribution. Omega, 33(4), 345-355.

de Kok, T. G., \& Visschers, J. W. (1999). Analysis of assembly systems with service level constraints. International Journal of Production Economics, 59(1), 313-326.

Fujiwara, O., Yue, X., Sangaradas, K., \& Luong, H. T. (1998). Evaluation of performance measures for multi-part, single-product Kanban controlled assembly systems with stochastic acquisition and production lead times. International Journal of Production Research, 36(5), 1427-1444.

Gurnani, H., Akella, R., \& Lehoczky, J. (1996). Optimal order policies in assembly systems with random demand and random supplier delivery. IIE transactions, 28(11), 865-878.

Haixu, S., \& Bhaba, R. (1998). Designing a mixed-model assembly line to minimize the costs of idle and utility times. Computers \& industrial engineering,34(3), 609-628.

Michalewicz, Z. (1998). Genetic algorithms + data structures = evolution programs. springer.

Msimangira, K. A. (2003). Purchasing and supply chain management practices in Botswana. Supply Chain Management: An International Journal, 8(1), 7-11.

Nasiri, G. R., Davoudpour, H., \& Karimi, B. (2010). The impact of integrated analysis on supply chain management: a coordinated approach for inventory control policy. Supply Chain Management: An International Journal, 15(4), 277-289.

Nonino, F., \& Panizzolo, R. (2007). Integrated production/distribution planning in the supply chain: the Febal case study. Supply Chain Management: An International Journal, 12(2), 150-163.

Park, M. W., \& Kim, Y. D. (1999). A heuristic algorithm for a production planning problem in an assembly system. Journal of the Operational Research Society, 50(2), 138-147.

Park, M. W., \& Kim, Y. D. (2000). A branch and bound algorithm for a production scheduling problem in an assembly system under due date constraints. European Journal of Operational Research, 123(3), 504-518.

Powell, S. G., \& Pyke, D. F. (1998). Buffering unbalanced assembly systems. IIE transactions, 30(1), 55-65.

Rosenblatt, M. J., \& Lee, H. L. (1996). The effects of work-in-process inventory costs on the design and scheduling of assembly lines with low throughput and high component costs. IIE transactions, 28(5), 405-414. 
Sadeghi Moghadam, M. R., Afsar, A., \& Sohrabi, B. (2008). Inventory lot-sizing with supplier selection using hybrid intelligent algorithm. Applied Soft Computing, 8(4), 1523-1529.

Samaranayake, P. (2005). A conceptual framework for supply chain management: a structural integration. Supply Chain Management: An International Journal, 10(1), 47-59.

Sarker, R., \& Newton, C. (2002). A genetic algorithm for solving economic lot size scheduling problem. Computers \& Industrial Engineering, 42(2), 189-198.

Simatupang, T. M., Sandroto, I. V., \& Lubis, S. H. (2004). Supply chain coordination in a fashion firm. Supply Chain Management: An International Journal, 9(3), 256-268.

Woarawichai C., Kullpattaranirun T. and Rungreunganun V. (2010). Applying genetic algorithms for inventory lot-sizing problem with supplier selection under storage space. Asian International Journal of Science and Technology in Production and Manufacturing Engineering, 3(4), 37-45. 